\title{
Risk factors and coping strategies of severe community-acquired pneumonia in chemotherapy induction period of acute leukemia
}

\author{
NING LI ${ }^{1 *}$, QINGCHENG DUAN ${ }^{2 *}$ and WEIDAN ZHANG ${ }^{2}$ \\ Departments of ${ }^{1}$ Hematology and ${ }^{2}$ Emergency, Dezhou People's Hospital, Dezhou, Shandong 253014, P.R. China
}

Received July 28, 2017; Accepted December 6, 2017

DOI: $10.3892 / \mathrm{ol} .2018 .7731$

\begin{abstract}
The risk factors and coping strategies of severe community-acquired pneumonia (SCAP) in chemotherapy induction period of acute leukemia were investigated. Eighty-six patients with CAP in chemotherapy induction period of acute leukemia in Dezhou Hospital from March 2014 to February 2017 were selected and divided into observation group (SCAP group, $n=45$ ) and control group (non-SCAP group, $n=41$ ) according to the acute physiology and chronic health evolution II (APACHE II) score. The blood, sputum, nasopharyngeal secretion and pleural effusion samples were collected from patients in both groups, and the samples were detected for pathogens, followed by the analysis of relevant factors. The dynamic changes in the sequential organ failure assessment (SOFA) score, procalcitonin (PCT), D-dimer (D-D) and C-reactive protein (CRP) levels in patients were observed before and after the corresponding treatment strategies were taken. The total distribution ratio of pathogens from high to low in the two groups was as follows: bacterium, virus, fungus, mycoplasma and chlamydia trachomatis; there was no significant difference between the two groups $(\mathrm{P}>0.05)$. Logistic regression analysis showed that the repeated infection $(\mathrm{OR}=3.315, \mathrm{P}=0.005)$, multi-resistant bacterial infection $(\mathrm{OR}=1.915, \mathrm{P}=0.008)$ and $\mathrm{D}-\mathrm{D}(\mathrm{OR}=1.936, \mathrm{P}=0.009)$ were independent risk factors for SCAP $(\mathrm{P}<0.05)$. After different coping strategies were taken, the SOFA score, PCT, D-D and CRP levels in the two groups were significantly decreased, and they were obviously higher in observation group than those in control group $(\mathrm{P}<0.05)$. Repeated infection, $\mathrm{D}-\mathrm{D}$ level and multi-resistant bacterial infection are the risk factors affecting the SCAP in chemotherapy induction period of acute leukemia. The coping strategies can effectively relieve the
\end{abstract}

Correspondence to: Dr Weidan Zhang, Department of Emergency, Dezhou People's Hospital, 1751 Xinhu Street, Dezhou, Shandong 253014, P.R. China

E-mail:1wnbnb22@126.com

*Contributed equally

Key words: acute leukemia, chemotherapy induction period, community-acquired pneumonia patient's condition, reduce the severity of disease and improve the survival rate of patients.

\section{Introduction}

Acute leukemia (AL) is a malignant tumor of the blood system and frequently occurs in children with a high mortality rate, three quarters of the cases are acute lymphoblastic leukemia $(1,2)$. At present,chemotherapy dominates in the treatment method of AL. In the chemotherapy induction period of AL, patients often suffer from fever and infection, the latter of which is the main complication in the chemotherapy induction period, as well as the leading cause of death of patients (3). Community-acquired pneumonia (CAP) is an infectious pulmonary parenchymal inflammation; in particular, severe community-acquired pneumonia (SCAP) has not only respiratory symptoms and respiratory failure, but also septic shock, sepsis and other manifestations involving other systems (4). Under the influence of chemotherapy drugs, patients in chemotherapy induction period of AL suffer from low immune function, invasion of a variety of pathogens and accompanying SCAP, which not only seriously threatens the health of patients, but also greatly increases the fatality rate. Moreover, it consumes many medical resources and brings a heavy economic burden to the family and society $(5,6)$. In order to understand the risk factors of SCAP in the chemotherapy induction period of AL and to develop the corresponding prevention and control strategies, this investigation was performed.

\section{Patients and methods}

General materials. Eighty-six patients with CAP in chemotherapy induction period of AL treated in Dezhou Hospital from March 2014 to February 2017 were selected as the objects of study. Inclusion criteria: 1) patients diagnosed as AL via bone marrow puncture; 2) patients in chemotherapy induction period meeting the diagnostic criteria of CAP; 3) patients who signed the informed consent. Exclusion criteria: 1) patients with pulmonary embolism and suspicious pulmonary embolism; 2) patients without complete clinical data, affecting the score. Patients enrolled were divided into observation group (SCAP group, $n=45$ ) and control group (non-SCAP group, $\mathrm{n}=41$ ) according to the acute physiology and chronic health evolution II (APACHE II) score. There were no statistically 
Table I. General materials of objects of study.

\begin{tabular}{lcccc}
\hline Item & Observation group $(\mathrm{n}=45)$ & Control group $(\mathrm{n}=41)$ & $\mathrm{t} / \chi^{2}$ test & P-value \\
\hline Sex (male/female) & $24 / 21$ & $21 / 20$ & 0.001 & 0.984 \\
Age (years) & $0-25$ & $1-26$ & & \\
Average age (years) & $17.86 \pm 3.49$ & $17.75 \pm 3.52$ & 0.145 & 0.885 \\
Weight (kg) & $52.43 \pm 3.26$ & $52.85 \pm 3.18$ & 0.604 & 0.547 \\
Acute lymphoblastic leukemia & $38(84.44)$ & $36(87.80)$ & 0.019 & 0.891 \\
Acute non-lymphocytic leukemia & $7(15.56)$ & $5(12.20)$ & & \\
\hline
\end{tabular}

significant differences in the general conditions between the two groups $(\mathrm{P}>0.05)$ (Table I).

Chemotherapy induction period. Patients in the two groups were treated with remission induction therapy using CCLG-08: 1) Days 1-7: Prednisone tablets (Pred) were given at a dose of $60 \mathrm{mg} /\left(\mathrm{m}^{2} \mathrm{x}\right.$ days $\left.) ; 2\right)$ day day 8 : Pred was withdrawn and Dex was given; the dose was reduced from day 29 , reduced by half within 3 days and withdrawn within 9 days; DNR was given twice at days 8 and 15 at a dose of $30 \mathrm{mg} / \mathrm{m}^{2}$ each time; L-ASP was given at days $8,15,22$ and 29 once every 3 days at a dose of $5000 \mathrm{U} / \mathrm{m}^{2}$ each time; VCR was give for a total of 8 times at days $8,11,14,17,20,23,26$ and 29 at a dose of $1.5 \mathrm{mg} / \mathrm{m}^{2}$ each time; 3) Patients were treated with MTX at 1,15 and 33 days. The study was approved by the Ethics Committee of Dezhou People's Hospital (Shandong, China).

\section{Coping strategies}

Relevant treatment. Once being diagnosed as CAP, patients were treated with empirical antibiotic treatment first and antibiotic de-escalation therapy to stabilize the disease to the full extent; the individualized drug was selected according to the multi-resistant bacterial infection, and the initial experiential therapy was transformed into the targeted therapy later. The corresponding strategy was taken for different complications: patients complicated with respiratory failure should be treated with ventilator for oxygen inhalation to improve the ventilation; patients complicated with empyema should be treated with thoracocentesis to detect whether it was transudate or pus, and early drainage should be performed as soon as possible; patients with septic shock should be treated with small- and medium-dose glucocorticoid; and patients with infectious shock should be treated with $300 \mathrm{mg}$ hydrocortisone every day.

Nursing cooperation. Patients should be cared during the treatment, including: 1) environmental nursing: nurses should strengthen the ward management, isolate and disinfect, and regularly ventilate the ward and disinfect the air; 2) nursing procedure: nurses should strictly implement the aseptic operations and all nursing procedures together, clean the hands to avoid cross infection; 3 ) oral nursing: nurses should guide patients to clean the mouth with normal saline after three meals, before going to bed and getting up in the morning; those with fungal infection should clean their mouth with $2 \%$ sodium bicarbonate; 4) skin care: patient's skin should be kept clean through the hip bath using patassium permanganate solution $(1: 5,000)$ before going to bed and after toilet every day, and nurses should observe the skin fold of the whole body of patients every day to check whether there was any sign of infection.

Evaluation indexes. Patients' condition was evaluated using the sequential organ failure assessment (SOFA) score developed by the European Society of Intensive Care Medicine (ESICM) (7), and the respiratory system, coagulation system, liver, circulatory system, neurological system and renal system were scored (0-4 points). The score of each item was added to obtain the total score, and the total score was positively correlated with the severity of disease.

Before treatment and at 3,5 and 7 days after treatment, the serum procalcitonin (PCT) level was detected via enzyme-linked fluorescent assay (ELFA), the serum C-reactive protein (CRP) level was detected via enzyme-linked immunosorbent assay (ELISA) and the serum D-dimer (D-D) level was detected via immunoturbidimetric method. The relevant kits were provided by Beckman Coulter, Miami, FL, USA, and the operations were in strict accordance with the kit instructions.

Statistical analysis. Data were processed using SPSS 19.0 (SPSS Inc., Chicago, IL, USA) software. Measurement data were presented as mean \pm standard deviation, and t-test was used; enumeration data were presented as ratio, and Chi-square test was used; Logistic regression analysis was used for the influencing factors of SCAP. P $<0.05$ was considered to indicate a statistically significant difference.

\section{Results}

Total distribution of pathogens in patients in the two groups. The total distribution ratio of pathogens from high to low in the two groups was as follows: bacterium, virus, fungus, mycoplasma and Chlamydia trachomatis; there was no significant difference between the two groups $(\mathrm{P}>0.05)$ (Table II).

Analysis of the relevant factors affecting SCAP. Univariate analysis showed that the repeated infection, SOFA score, PCT, D-D and CRP levels and multi-resistant bacterial infection had influence on SCAP $(\mathrm{P}<0.05)$ (Table III).

Analysis of influencing factors of SCAP. With the occurrence of SCAP as a dependent variable, and with repeated infection, multi-resistant bacterial infection, SOFA score, PCT, D-D and 
Table II. Total distribution of pathogens in patients in the two groups.

\begin{tabular}{lccc}
\hline Pathogen & Observation group $(\mathrm{n}=45)$ & Control group $(\mathrm{n}=41)$ & $\chi^{2}$ test \\
\hline Bacterium & $19(42.22)$ & $16(39.02)$ & 0.339 \\
Virus & $10(22.22)$ & $11(26.83)$ & 0.987 \\
Fungus & $7(15.56)$ & $6(14.63)$ & $5(12.20)$ \\
Mycoplasma & $5(11.11)$ & $3(7.32)$ & \\
Chlamydia trachomatis & $4(8.89)$ & & \\
\hline
\end{tabular}

Table III. Univariate analysis of influencing factors of SCAP.

\begin{tabular}{|c|c|c|c|c|}
\hline Factor & Observation group $(n=45)$ & Control group $(n=41)$ & $\mathrm{t} / \chi^{2}$ test & P-value \\
\hline $\operatorname{Sex}(\mathrm{n}, \%)$ & & & 0.001 & 0.984 \\
\hline Male & $24(53.33)$ & $21(51.22)$ & & \\
\hline Female & $21(46.67)$ & $20(48.78)$ & & \\
\hline Age & $17.86 \pm 3.49$ & $17.75 \pm 3.52$ & 0.145 & 0.885 \\
\hline Respiratory rate & $37.86 \pm 3.49$ & $38.25 \pm 3.52$ & 0.515 & 0.608 \\
\hline Long-term bed rest $(\mathrm{n}, \%)$ & & & 0.007 & 0.935 \\
\hline Yes & $19(42.22)$ & $16(39.02)$ & & \\
\hline No & $26(57.78)$ & $25(60.98)$ & & \\
\hline Repeated infection (n, \%) & & & 9.291 & 0.002 \\
\hline Yes & $37(82.22)$ & $20(48.78)$ & & \\
\hline No & $8(17.78)$ & $21(51.22)$ & & \\
\hline SOFA score & $9.85 \pm 3.13$ & $7.32 \pm 3.18$ & 3.716 & $<0.001$ \\
\hline PCT (ng/ml) & $5.89 \pm 3.23$ & $3.36 \pm 3.28$ & 3.601 & 0.001 \\
\hline D-D (ng/ml) & $847.89 \pm 31.43$ & $523.83 \pm 26.34$ & 51.549 & $<0.001$ \\
\hline CRP (mg/l) & $127.35 \pm 14.23$ & $67.37 \pm 9.26$ & 22.922 & $<0.001$ \\
\hline Multi-resistant bacterial infection & & & 16.560 & $<0.001$ \\
\hline Yes & $35(77.78)$ & $17(41.46)$ & & \\
\hline No & $10(22.22)$ & $24(58.54)$ & & \\
\hline
\end{tabular}

SCAP, severe community-acquired pneumonia; SOFA, sequential organ failure assessment; PCT, procalcitonin; D-D, D-dimer; CRP, C-reactive protein.

CRP levels as independent variables, Logistic regression analysis showed that the repeated infection $(\mathrm{OR}=3.315$, $\mathrm{P}=0.005)$, multi-resistant bacterial infection $(\mathrm{OR}=1.915$, $\mathrm{P}=0.008)$ and $\mathrm{D}-\mathrm{D}(\mathrm{OR}=1.936, \mathrm{P}=0.009)$ were independent risk factors for SCAP $(\mathrm{P}<0.05)$ (Table IV).

Comparisons of SOFA score, PCT, D-D and CRP levels in patients. At 3, 5 and 7 days after treatment strategies were taken, the SOFA score, PCT, D-D and CRP levels in the two groups were significantly decreased, and they were obviously higher in observation group than those in control group $(\mathrm{P}<0.05)$ (Tables V-VIII).

\section{Discussion}

With the progress in cytogenetics, molecular biology and other medical technologies, the remission rate of AL has greatly improved and reached more than $90 \%$, and the 5-year survival rate of patients can also reach more than $80 \%$ (8). However, the infection in the chemotherapy induction period is the leading cause of death of patients, mainly because the chemotherapy induction period is long, and patients have to receive chemotherapy every week, so the bone marrow suppression is obvious and granulocyte deficiency lasts for a long time. Besides, the disease itself will damage the humoral immunity and cellular immunity, the patient's immunity is decreased, combined with a large number of side effects due to long-term application of chemotherapy drugs, so the normal mucosal barriers of digestive tract and respiratory tract will be damaged (9-10). AL patients are susceptible to the invasion of pathogenic bacteria, thus suffering from infection, mainly respiratory virus infection that frequently occurs in the lungs (11).

When the pathogen invades the lower respiratory tract of AL patients, it will cause structural and functional damage to 
Table IV. Logistic regression analysis of influencing factors of SCAP.

\begin{tabular}{|c|c|c|c|c|c|c|}
\hline Factor & $\beta$ & $\mathrm{SE}$ & Wald & OR & $95 \% \mathrm{CI}$ & P-value \\
\hline Repeated infection & 0.767 & 0.673 & 5.421 & 3.315 & $1.106-5.854$ & 0.005 \\
\hline CRP & 0.605 & 0.504 & 3.425 & 0.946 & $0.196-1.142$ & 0.212 \\
\hline D-D & 0.566 & 0.649 & 6.753 & 1.936 & $1.075-3.212$ & 0.009 \\
\hline Multi-resistant bacterial infection & 0.633 & 0.417 & 5.524 & 1.915 & $1.103-3.347$ & 0.008 \\
\hline PCT & 0.156 & 0.446 & 2.703 & 0.734 & $0.275-0.912$ & 0.306 \\
\hline SOFA score & 0.315 & 0.486 & 3.292 & 0.846 & $0.225-1.373$ & 0.213 \\
\hline
\end{tabular}

SCAP, severe community-acquired pneumonia; CRP, C-reactive protein; D-D, D-dimer; PCT, procalcitonin; SOFA, sequential organ failure assessment.

Table V. Comparison of sequential organ failure assessment (SOFA) scores of patients between the two groups in different time.

\begin{tabular}{|c|c|c|c|c|c|c|c|}
\hline Group & $\mathrm{n}$ & Before treatment & 3 days & 5 days & 7 days & F-value & P-value \\
\hline Observation group & 45 & $9.85 \pm 3.13$ & $8.72 \pm 3.21$ & $8.04 \pm 2.34$ & $7.03 \pm 2.04$ & 26.134 & $<0.001$ \\
\hline Control group & 41 & $7.32 \pm 3.18$ & $6.64 \pm 3.38$ & $5.52 \pm 2.47$ & $5.09 \pm 2.13$ & 18.512 & $<0.001$ \\
\hline t-test & & 3.716 & 2.926 & 4.858 & 4.313 & & \\
\hline P-value & & $<0.001$ & 0.004 & $<0.001$ & $<0.001$ & & \\
\hline
\end{tabular}

Table VI. Comparison of procalcitonin (PCT) levels in patients between the two groups in different time (ng/ml).

\begin{tabular}{|c|c|c|c|c|c|c|c|}
\hline Group & $\mathrm{n}$ & Before treatment & 3 days & 5 days & 7 days & F-value & P-value \\
\hline Observation group & 45 & $5.89 \pm 3.23$ & $3.32 \pm 1.15$ & $2.23 \pm 1.04$ & $1.15 \pm 0.83$ & 18.718 & $<0.001$ \\
\hline Control group & 41 & $3.36 \pm 3.28$ & $2.54 \pm 1.47$ & $1.53 \pm 0.75$ & $0.78 \pm 0.44$ & 27.432 & $<0.001$ \\
\hline t-test & & 3.601 & 2.753 & 3.549 & 2.812 & & \\
\hline P-value & & $<0.001$ & 0.007 & 0.001 & 0.005 & & \\
\hline
\end{tabular}

Table VII. Comparison of D-dimer (D-D) levels in patients between the two groups in different time (ng/ml).

\begin{tabular}{|c|c|c|c|c|c|c|c|}
\hline Group & $\mathrm{n}$ & Before treatment & 3 days & 5 days & 7 days & F-value & P-value \\
\hline Observation group & 45 & $847.89 \pm 31.43$ & $785.98 \pm 28.15$ & $604.84 \pm 21.04$ & $562.48 \pm 19.02$ & 48.643 & $<0.001$ \\
\hline Control group & 41 & $523.83 \pm 26.34$ & $466.89 \pm 21.27$ & $315.72 \pm 19.35$ & $284.65 \pm 15.24$ & 43.726 & $<0.001$ \\
\hline t-test & & 51.549 & 58.859 & 66.121 & 74.285 & & \\
\hline P-value & & $<0.001$ & $<0.001$ & $<0.001$ & $<0.001$ & & \\
\hline
\end{tabular}

lung and tracheal tissues, lead to the changes in respiratory rhythm and frequency, dyspnea and other serious respiratory symptoms. CAP frequently occurs, which is closely related to the immune, defense and hematopoietic dysfunction, application of chemotherapy drugs, hormones and broad-spectrum antibiotics and long LOS due to induction therapy (12-14). The results of this study showed that the total distribution ratio of pathogens from high to low in the two groups was as follows: bacterium, virus, fungus, mycoplasma and chlamydia trachomatis; there was no significant difference between the groups $(\mathrm{P}>0.05)$, indicating that the infection pathogens of either SCAP or non-SCAP patients are mostly bacteria and viruses.

In this study, Logistic regression analysis showed that the repeated infection $(\mathrm{OR}=3.315, \mathrm{P}=0.005)$, multi-resistant bacterial infection $(\mathrm{OR}=1.915, \mathrm{P}=0.008)$ and $\mathrm{D}-\mathrm{D}(\mathrm{OR}=1.936$, $\mathrm{P}=0.009)$ were independent risk factors for SCAP $(\mathrm{P}<0.05)$. This is because Gram-negative bacteria dominate in the infectious bacteria of SCAP, and Pseudomonas aeruginosa is the most common, followed by Klebsiella pneumoniae, 
Table VIII. Comparison of C-reactive protein (CRP) levels in patients between the two groups at different times (ng/ml).

\begin{tabular}{|c|c|c|c|c|c|c|c|}
\hline Group & $\mathrm{n}$ & Before treatment & 3 days & 5 days & 7 days & F-value & P-value \\
\hline Observation group & 45 & $127.35 \pm 14.23$ & $105.38 \pm 11.35$ & $84.54 \pm 9.14$ & $62.09 \pm 8.12$ & 41.603 & $<0.001$ \\
\hline Control group & 41 & $67.37 \pm 9.26$ & $56.27 \pm 7.46$ & $45.32 \pm 5.42$ & $34.37 \pm 3.48$ & 29.456 & $<0.001$ \\
\hline t-test & & 22.922 & 23.464 & 23.905 & 20.224 & & \\
\hline P-value & & $<0.001$ & $<0.001$ & $<0.001$ & $<0.001$ & & \\
\hline
\end{tabular}

Staphylococcus aureus and Staphylococcus epidermidis (15). With the repeated infection, changes in pathogenic bacteria and increased bacterial resistance in patients, multi-resistant bacterial infection will be caused. If it is not controlled satisfactorily, multi-resistant bacterial infection will lead to multiple organ dysfunction and internal environment disorders, so patients are prone to SCAP and suffer from multiple organ failure, eventually leading to death. When the D-D level is too high, the risks of vasoactive agent or mechanical ventilation will be increased for CAP patients. Moreover, D-D plays an important role in the occurrence and development of inflammation and the disease will constantly progress into SCAP.

Organic damage in SCAP patients will release a variety of markers, such as PCT, CRP and D-D. The detection of these markers can predict the prognosis (16). PCT is a precursor of calcitonin, which is an inflammatory factor without hormone activity, as well as a commonly-used marker in clinic. It is produced by the thyroid gland in a normal state and its level is low $(<0.0025 \mu \mathrm{g} / \mathrm{ml})(17)$, so it is almost undetectable. When infection occurs, other organs will release PCT. In the 1930s, CRP, as a kind of acute-phase response protein, was found. When the body is infected, CRP concentration will be rapidly increased under the stimulation of invasion factors. Therefore, it is often used as an inflammatory marker in clinical practice. Moreover, the CRP level will increase with the increase in CAP severity (18). D-D is the smallest fragment of specific product after fibrous protein is hydrolyzed by plasmin, which can reflect the formation of thrombin and the activity of plasmin. Its content in the body is less than $280 \mathrm{ng} / \mathrm{ml}$ and even undetectable in normal state (19). D-D plays an important role in the occurrence and development of inflammation. When the body is infected, a variety of inflammatory factors will be released, damaging the vascular endothelial cells and resulting in decline in function, which activates the coagulation system, consumes a large number of coagulation factors and causes the patient's blood into hypercoagulable state (20). The results of this study showed that at 3,5 and 7 days after effective treatment strategies were taken, the SOFA score, PCT, D-D and CRP levels in the two groups were significantly decreased, and they were obviously higher in observation group than those in the control group $(\mathrm{P}<0.05)$. This is because of the targeted therapeutic regimens and careful nursing, thus alleviating the patient's inflammation and effectively controlling infection. After the stimulations of inflammation-causing substances and invasive factors are eliminated, the concentrations of various markers will rapidly decline and even return to normal; the decline in SOFA score dynamically reflects the remission process of disease. The indexes of observation group were significantly higher than those of control group, which may be related to the fact that the serious conditions of patients are effectively alleviated through the effective intervention strategy, but the expected effects may not be achieved in a short-term.

In conclusion, repeated infection, a high D-D level and multi-resistant bacterial infection are risk factors of SCAP in the chemotherapy induction period of AL. After the corresponding coping strategies are taken, patient's condition and prognosis can be effectively evaluated through the dynamic monitoring of changes in PCT, CRP, D-D levels and SOFA score, thereby reducing the mortality rate.

\section{References}

1. Fransecky L, Mochmann LH and Baldus CD: Outlook on PI3K/AKT/mTOR inhibition in acute leukemia. Mol Cell Ther 3: 2, 2015.

2. Annesley CE and Brown P: Novel agents for the treatment of childhood acute leukemia. Ther Adv Hematol 6: 61-79, 2015.

3. Galloway-Peña JR, Smith DP, Sahasrabhojane P, Ajami NJ, Wadsworth WD, Daver NG, Chemaly RF, Marsh L, Ghantoji SS, Pemmaraju $\mathrm{N}$, et al: The role of the gastrointestinal microbiome in infectious complications during induction chemotherapy for acute myeloid leukemia. Cancer 122: 2186-2196, 2016.

4. Jain S, Self WH, Wunderink RG, Fakhran S, Balk R, Bramley AM, Reed C, Grijalva CG, Anderson EJ, Courtney DM, et al; CDC EPIC Study Team: Community-acquired pneumonia requiring hospitalization among U.S. adults. N Engl J Med 373: 415-427, 2015.

5. Gopakumar KG, Priyakumari T and Kusumakumary M: Infectious complications during induction chemotherapy in children with acute myeloid leukemia. Pediatr Hematol Oncol J 1: S15, 2016. doi: 10.1016/j.phoj.2016.10.038.

6. Avdonina MA, Abramov IS, Ammour YI and Nasedkina TV: Allelic variants of immune response genes in children with infectious complications during the treatment of acute leukemia. Mol Biol (Mosk) 51: 301-307, 2017 (In Russian).

7. Saleno CH, Camacho JR, Neto LM and Mendonca RG: P-177: The Sequential Organ Failure Assessment (SOFA) score is a predictive factor for 14-day mortality of elderly patients with advanced cancer who present to the ED. Eur Geriatr Med 2015: S79-S79, 1959.

8. Bleakley M, Heimfeld S, Loeb KR, Jones LA, Chaney C, Seropian S, Gooley TA, Sommermeyer F, Riddell SR and Shlomchik WD: Outcomes of acute leukemia patients transplanted with naive $\mathrm{T}$ cell-depleted stem cell grafts. J Clin Invest 125: 2677-2689, 2015.

9. Knaus HA,Kanakry CG,Luznik LandGojoI:Immunomodulatory drugs: Immune checkpoint agents in acute leukemia. Curr Drug Targets 18: 315-331, 2017.

10. Bigliardi S, Morselli M, Potenza L, Riva G, Coluccio V, Maccaferri M, Paolini A, Colaci E, Fantuzzi V, Soci F, et al: Epidemiology and clinical outcome of lower respiratory tract infections by respiratory syncytial virus or parainfluenza virus type 3 in adults receiving treatment for either acute leukemia or severe aplastic anemia: A retrospective single center study. Ann Hematol 94: 1931-1934, 2015. 
11. Shokouhi S, Tehrani S and Hemmatian M: Mixed pulmonary infection with Penicillium notatum and Pneumocystis jiroveci in a patient with acute myeloid leukemia. Tanaffos 15: 53-56, 2016.

12. Nie W, Huang Q, Chen Y and Yin X: Treatment of an elderly patient with acute myeloid leukemia and invasive pulmonary aspergillosis infection with combined allogeneic hematopoietic stem cells microtransplantation and voriconazole. Indian J Hematol Blood Transfus 32 (Suppl 1): 56-58, 2016.

13. Hakim H, Dallas R, Zhou Y, Pei D, Cheng C, Flynn PM, Pui $\mathrm{CH}$ and Jeha $\mathrm{S}$ : Acute respiratory infections in children and adolescents with acute lymphoblastic leukemia. Cancer 122 798-805, 2016

14. Sadarangani M, Harvey M, McDonald A, Speert DP and Dix D: Brain abscesses due to Aspergillus nidulans infection during induction chemotherapy for acute lymphoblastic leukemia. J Pediatr Hematol Oncol 37: e384-e386, 2015.

15. Kurai D, Sasaki Y, Saraya T, Ishii H, Tsukagoshi H, Kozawa K, Ryo A, Ishioka T, Kuroda M, Oishi K, et al: Pathogen profiles and molecular epidemiology of respiratory viruses in Japanese inpatients with community-acquired pneumonia. Respir Investig 54: 255-263, 2016.

16. Çolak A, Y1lmaz C, Toprak B and Aktoğu S: Procalcitonin and CRP as biomarkers in discrimination of community-acquired pneumonia and exacerbation of COPD. J Med Biochem 36: 122-126, 2017.
17. Rodríguez AH, Avilés-Jurado FX, Díaz E, Schuetz P, Trefler SI, Solé-Violán J, Cordero L, Vidaur L, Estella Á, Pozo Laderas JC, et al; SEMICYUC/GETGAG Working Group: Procalcitonin (PCT) levels for ruling-out bacterial coinfection in ICU patients with influenza: A CHAID decision-tree analysis. J Infect 72: 143-151, 2016.

18. Chou SC, Ko HW and Lin YC: CRP/IL-6/IL-10 Single-nucleotide polymorphisms correlate with the susceptibility and severity of community-acquired pneumonia. Genet Test Mol Biomarkers 20: 732-740, 2016.

19. Fukumoto K, Taniguchi T, Usami N, Kawaguchi K, Fukui T, Ishiguro F, Nakamura S and Yokoi K: Preoperative plasma $\mathrm{D}$-dimer level is an independent prognostic factor in patients with completely resected non-small cell lung cancer. Surg Today 45: 63-67, 2015.

20. Duarte JC, Tavares e Castro A, Silva R, Correia L, Simão A and Carvalho A: Prognostic value of plasma D-dimer level in adults with community-acquired pneumonia: A prospective study. Rev Port Pneumol 2006 21: 218-219, 2015.

This work is licensed under a Creative Commons Attribution-NonCommercial-NoDerivatives 4.0 International (CC BY-NC-ND 4.0) License. 